CERN-TH-5835/90

\title{
Higgs production by heavy ion scattering
}

\author{
K.J. Abraham \\ R. Laterveer \\ NIKHEF-H \\ Postbus 41882 \\ 1009 DB Amsterdam, the Netherlands \\ J.A.M. Vermaseren * \\ D. Zeppenfeld ${ }^{\dagger}$ \\ CERN, Geneva, Switzerland
}

\begin{abstract}
We compute the production cross section of the Standard Model Higgs by two photon processes in lead-lead collisions. We investigate several lead form factors and recently proposed impact parameter effects. No approximations are used for the underlying two photon mechanism. We also compare the Higgs signal with its main background, the two photon production of quark pairs.
\end{abstract}

* on leave from NIKHEF-H, Amsterdam, the Netherlands

$\dagger$ on leave from University of Wisconsin, Madison, WI 53706, USA

CERN-TH-5835/90

August 1990 


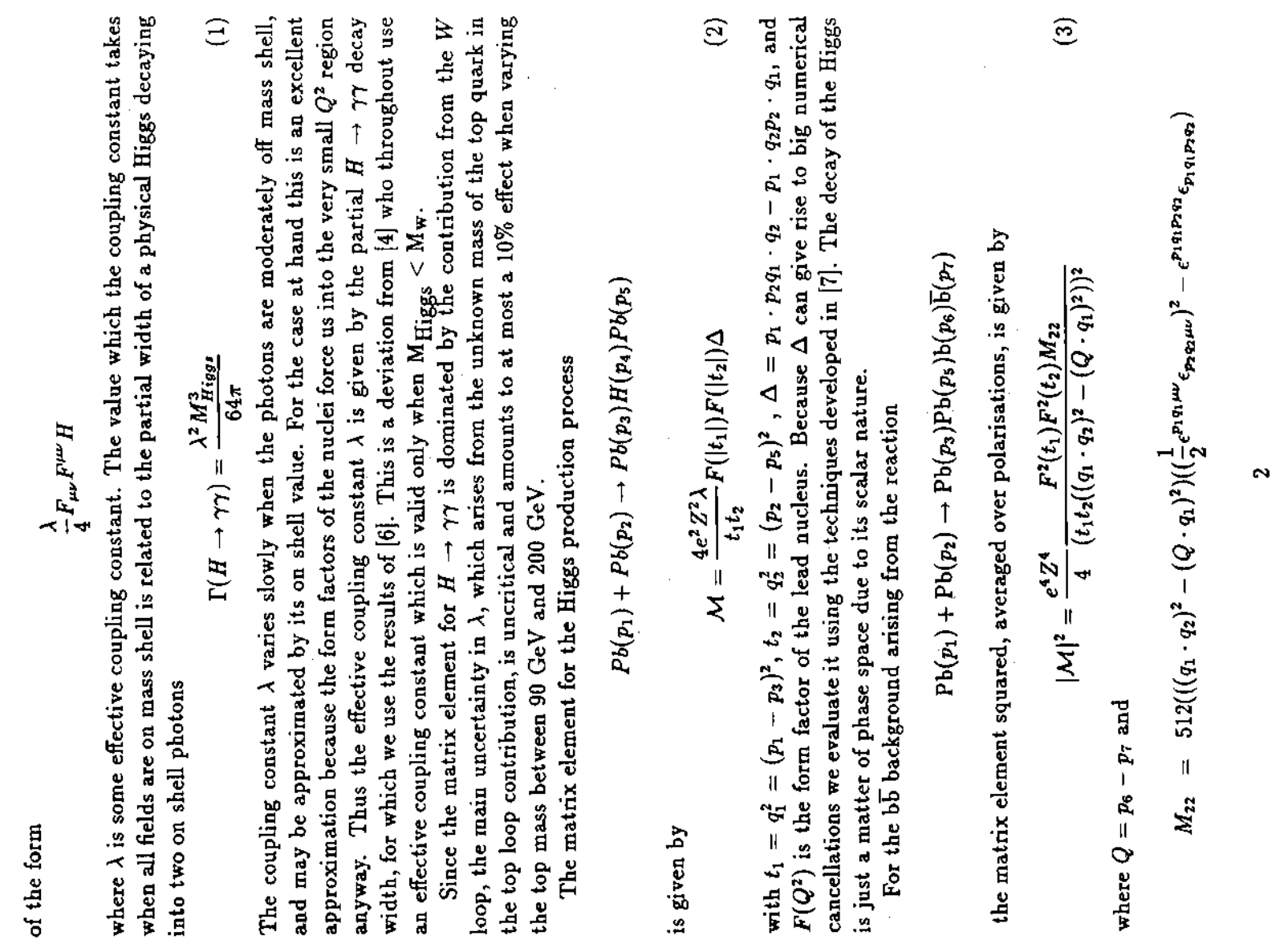

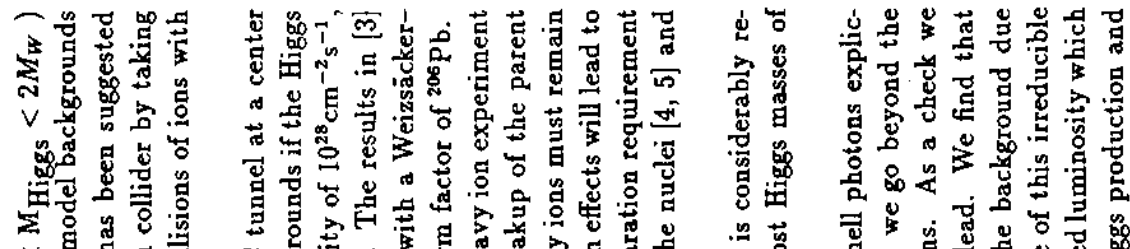

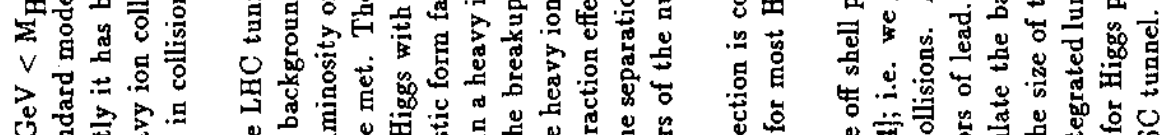

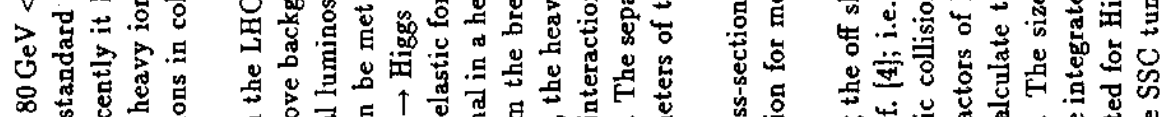

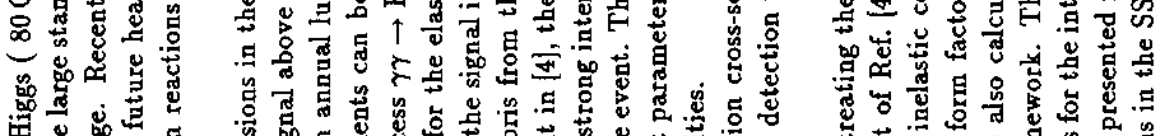

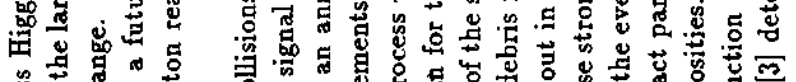

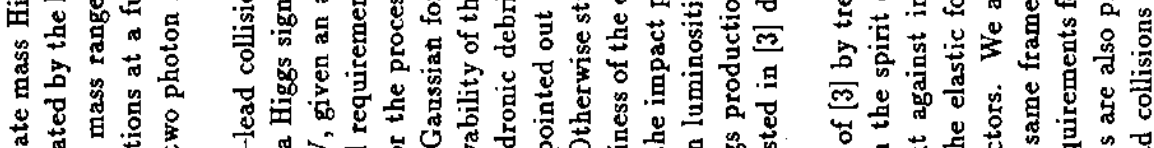

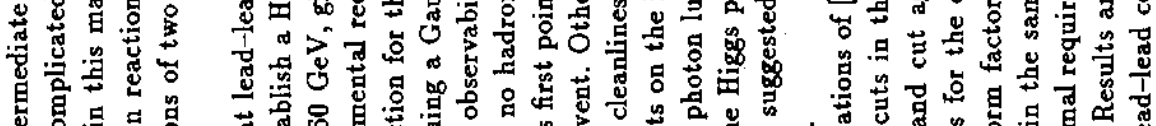

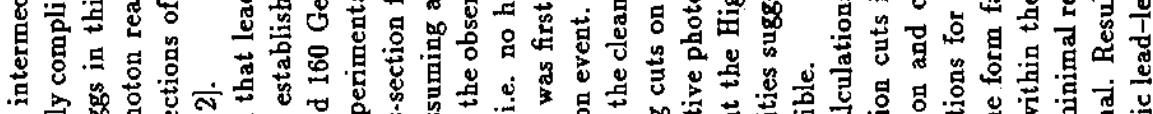

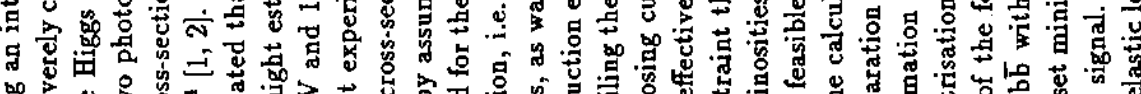

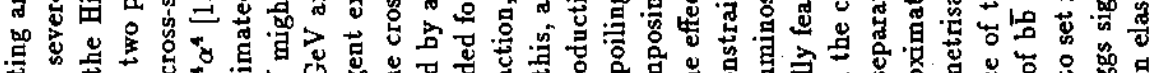

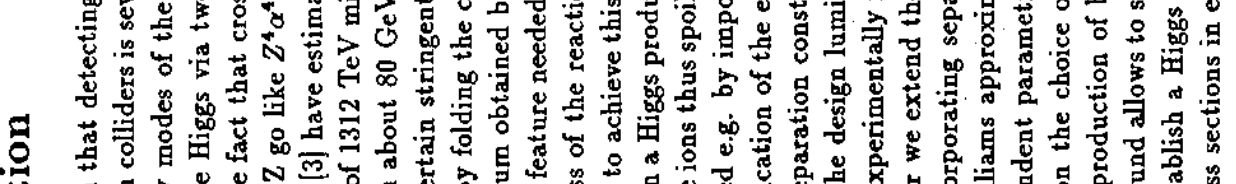

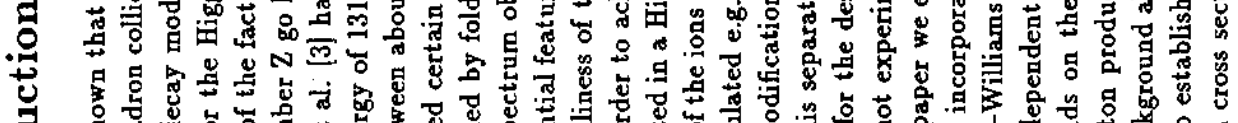

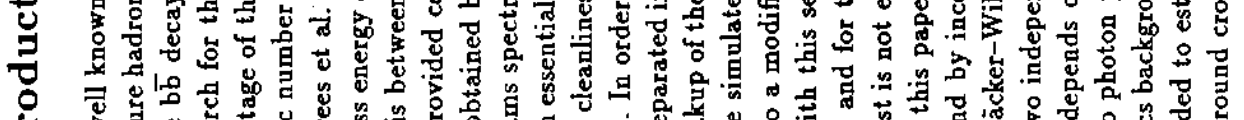

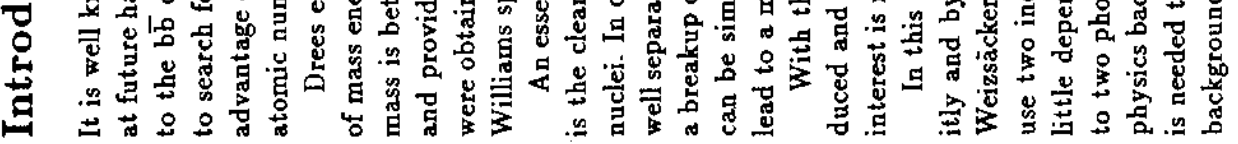




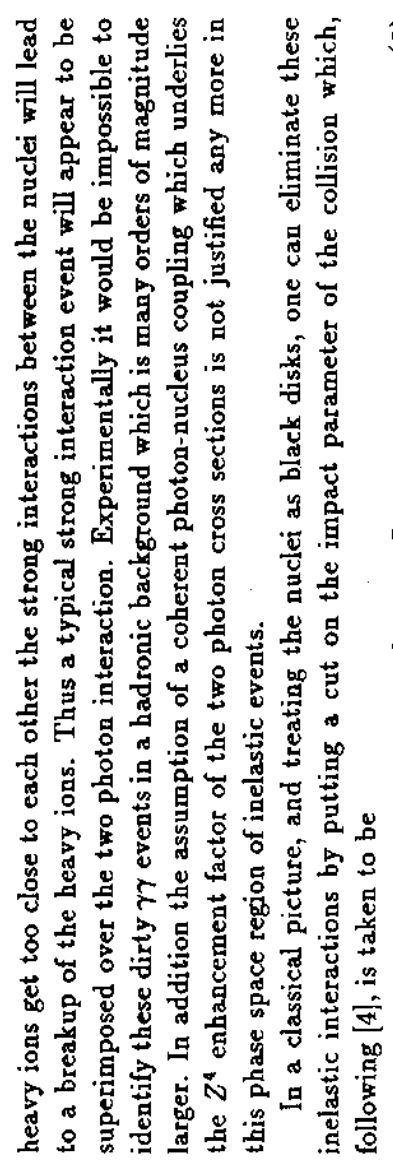

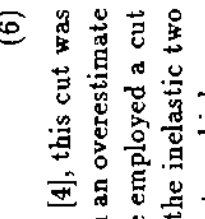

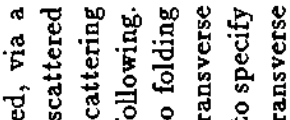

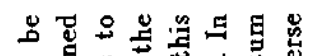

$\Xi \underset{c}{0}$

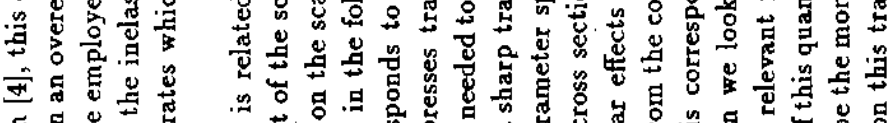

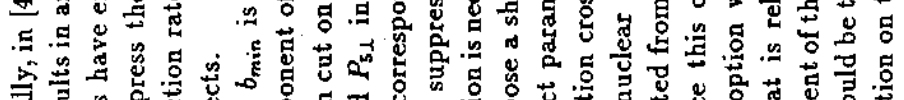

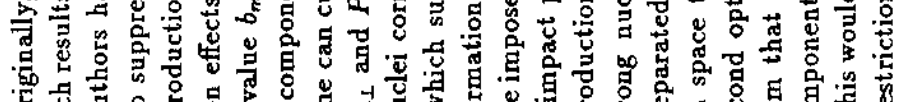

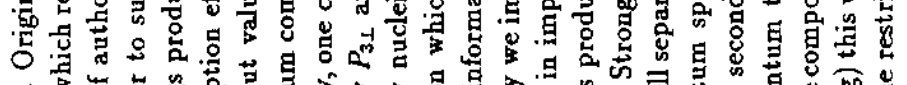

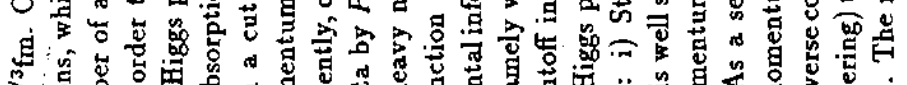

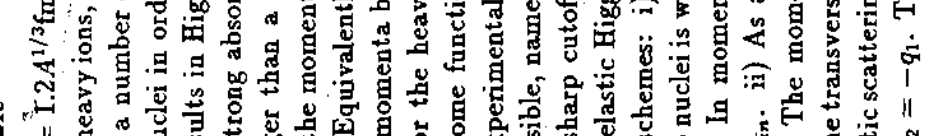

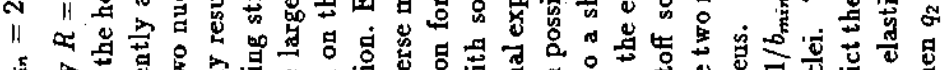

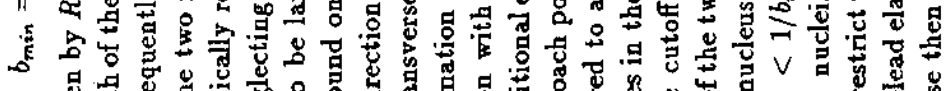

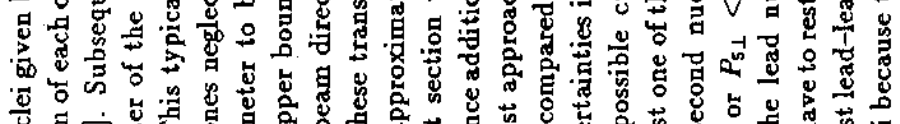

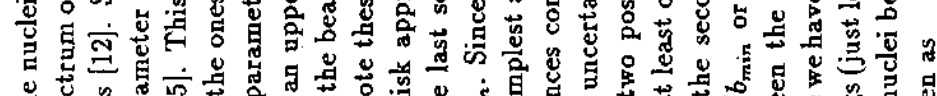

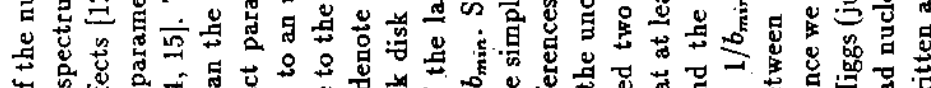

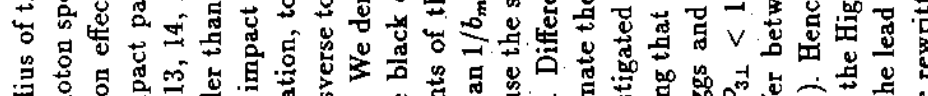

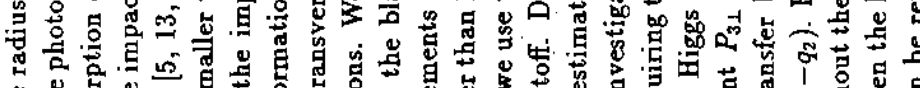

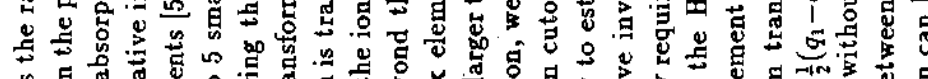

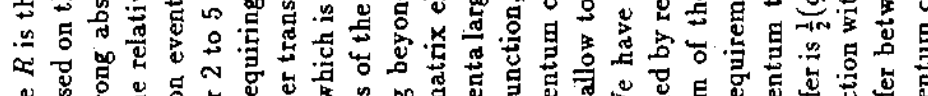

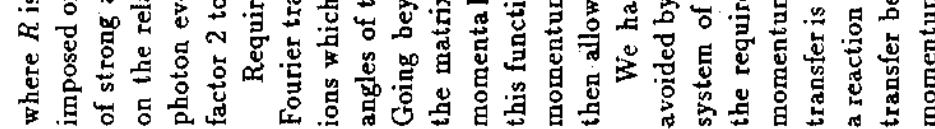



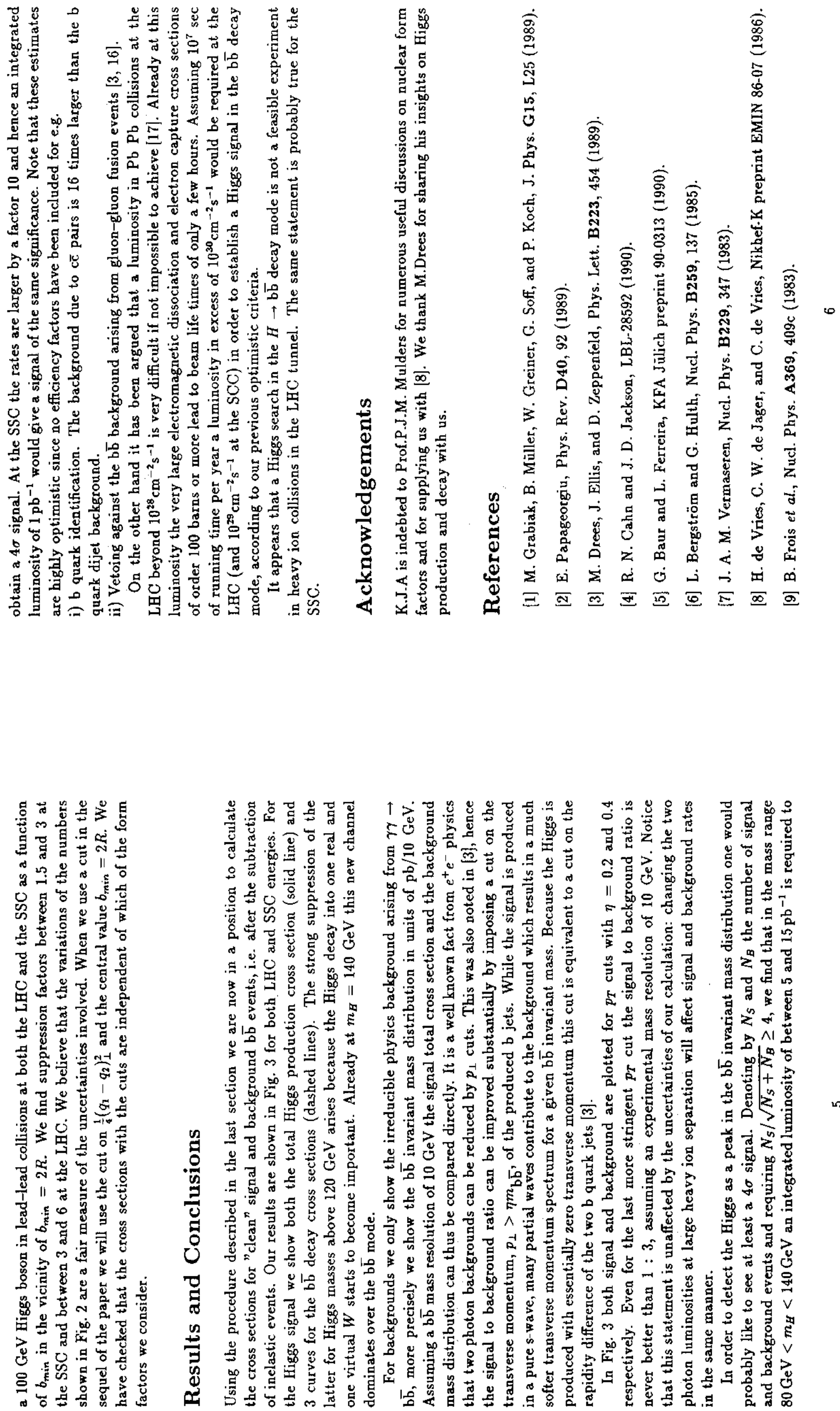

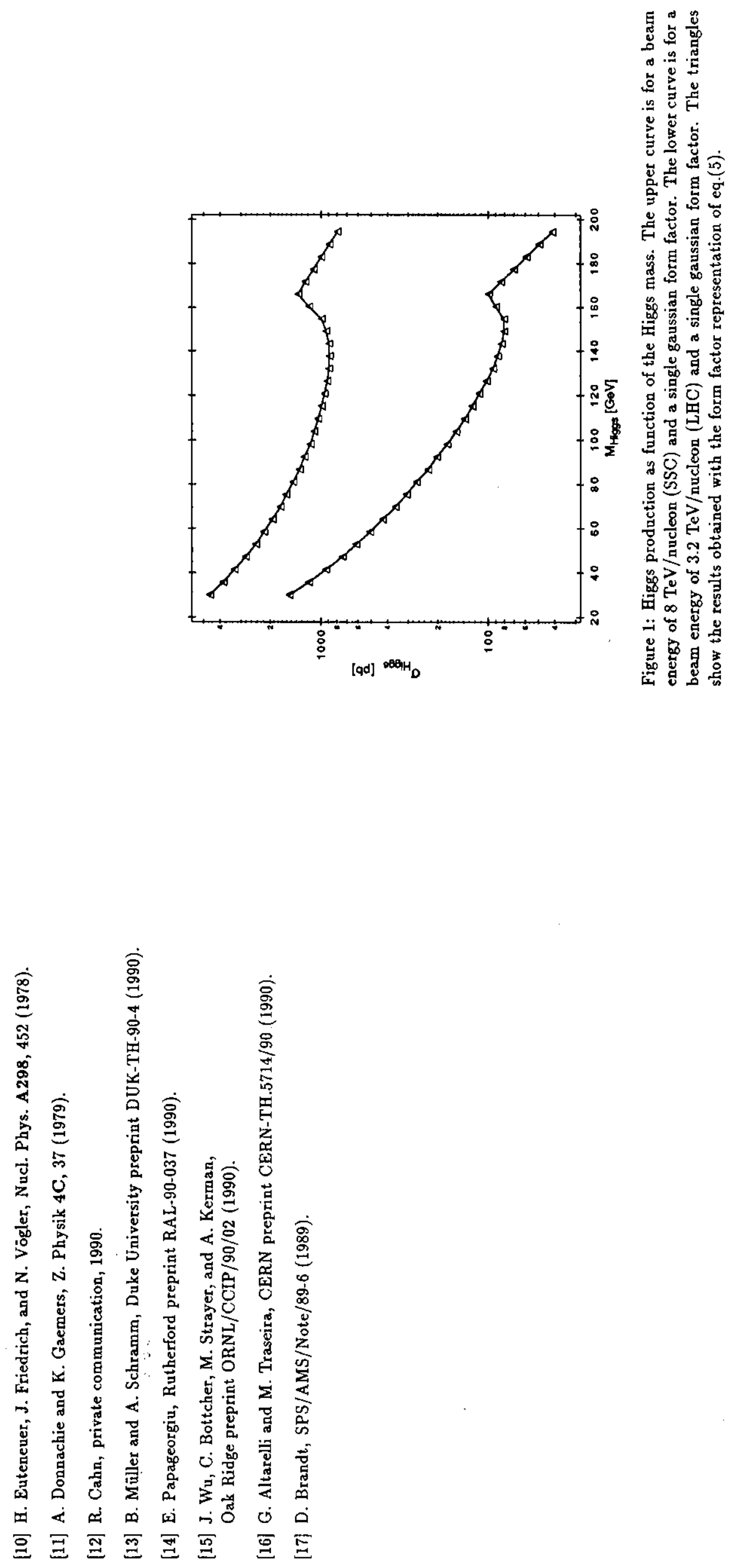

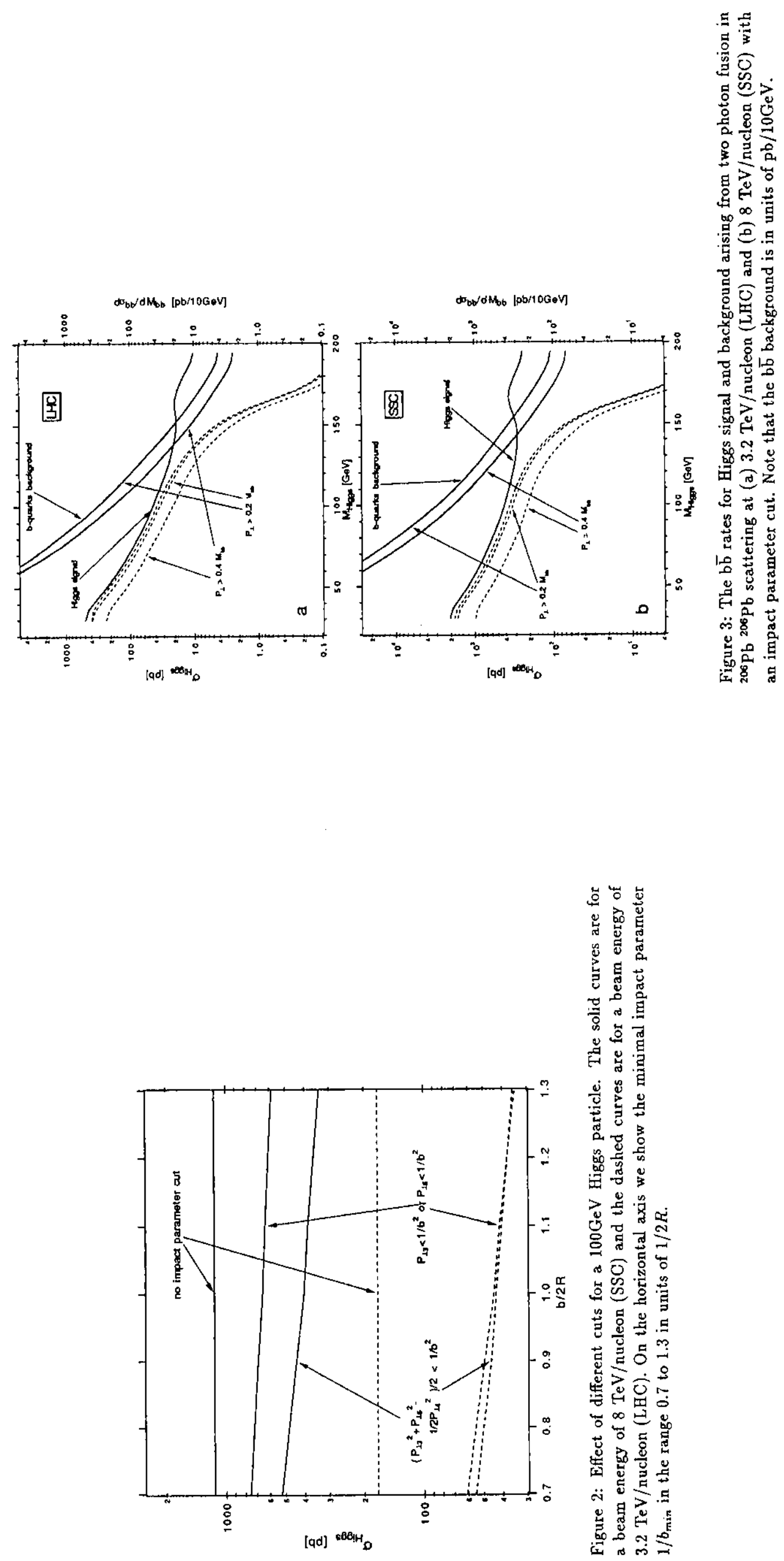

Imprimé au CERN. Prix : $0.25 \mathrm{Fr}$. 